\title{
REMOTE LEARNING DURING THE COVID-19 PANDEMIC FOR STUDENTS WITH LEARNING DISABILITIES: CHALLENGES AND OPPORTUNITIES
}

\author{
Egija Laganovska \\ University of Latvia, Latvia
}

\begin{abstract}
The situation in general education in Latvia has changed since the spring semester of 2020. On the $13^{\text {th }}$ of March 2020 Latvia temporarily introduced remote training at all stages of education. The government regularly monitored the spread of the COVID-19 virus and the number of infections, so restrictions in different areas have changed frequently. Educational institutions for students of $1^{\text {st }}-12^{\text {th }}$ grade (ages 6-17) in the 2020/2021 school year worked under fluctuating circumstances, and most of the learning process took place remotely. For most of the 2020/2021 school year, teaching and learning were thus largely based on technology and online teaching. The COVID-19 pandemic has had an impact on various aspects of life, such as the economy, education, and social life. This time has led to challenges as well as opportunities for students, teachers, and parents. It has also affected the learning process for students with learning disabilities.

For grades 1-12, the Individualised Education Plan (IEP) was developed in Latvia for students with learning disabilities. The IEP had to be adapted to the broader situation, and to work towards its betterment special education teachers participated in the preparation and organisation of the IEP.

The aim of this study is to explore the opinions of special education teachers and to examine what support measures are provided for students with learning disabilities during the COVID-19 pandemic. What are the challenges (barriers, obstacles) and what are the opportunities (benefits) of remote learning? Our research methods involved a literature analysis, a survey of special education teachers from Latvia, and a data collection effort and analysis. The study was conducted by distributing questionnaires via Google Forms. During this research, 70 special education teachers were surveyed.
\end{abstract}

Keywords: COVID-19 pandemic, remote learning, special educational teacher, students with learning disabilities. 


\section{Introduction}

Closures of schools, institutions, and other learning spaces impacted more than $94 \%$ of the world's student population (Pokhrel \& Chhetri, 2021). UNESCO has reported that 'Most governments around the world have temporarily closed educational institutions in an attempt to contain the spread of the COVID-19 pandemic. These nationwide closures are impacting over $60 \%$ of the world's student population. Several other countries have implemented localized closures impacting millions of additional learners'. Remote learning has transformed education, and the terminology involved describes many types of teaching situations (Qazi, 2021). Education can be imparted through multiple platforms such as traditional face-to-face delivery, e-education, and mixed methods. The COVID-19 Pandemic transformed the whole education process to be online, which translates into the form of e-learning in most schools worldwide. Remote learning integrates virtual technology in learning, which consequently allows for the continuation of the teaching and learning process throughout the pandemic (Saidi et al., 2021). The use of online platforms such as Google Classroom, Zoom, virtual learning environments, and social media, as well as various group forums such as Messenger, WhatsApp, and WeChat are explored and experimented with for teaching and learning opportunities for the sake of continuing education (Pokhrel \& Chhetri, 2021). The existing studies emphasise that in many lower income countries, more than half of the population does not have access to the internet (Avanesian et al., 2021). However, remote learning can increase inequalities in the quality of knowledge acquired between different students, which consequences an increasing of the risk of dropping out, and contributing to declining learning outcomes (Azevedo et al., 2020; Kaffenberger \& Pritchett, 2021). The COVID-19 pandemic has highlighted both challenges and opportunities in education. Students now need to learn how to work more independently, and teachers need to receive more training in the effective use of technological tools required for quality teaching. Furthermore, teachers have had difficulty in adapting to the use of information and communication technology (ICT) quickly (Ma et al., 2021).

Encouraging parental involvement in children's education should also be a priority (Brossard, 2020). A potential positive of online education is the idea that parents might become more familiar with their children's study habits, and might consequently be more able to play a positive role in their learning.

In Latvia, according to our survey data, $76 \%$ of respondents manage time well occasionally. The role of the state during the training is much more direct under these circumstances. $42 \%$ of people surveyed spend 3 
hours or more per day, assisting their children in their education (The Ministry of Education and Science, EDURIO, 2020). Students with learning disabilities have special needs in the learning process, including unique classroom, behavioural, physical, and social matters, and hence require a need-based adaptation of classroom procedures for effective learning. Screen time can be distracting or impersonal for certain children, especially those with learning disabilities. Increased electronic device usage may also negatively impact physical well-being by increasing eye strain, unhealthy eating habits, and poor sleep hygiene (Sheen et al., 2020).

Learning difficulties are often due to pedagogical failures, social circumstances, or other conditions that interfere with learning and are not related to medical diagnosis. Learning disabilities, however, are of neurobiological origin and affect the brain's ability to understand, remember, or communicate information. Specialists also distinguish between specific learning disorders: dyslexia - reduced reading ability; dysgraphia - reduced writing ability; dyscalculia - problems with performing mathematical activities; as well as the lesser known dyspraxia - motor dysfunction. Individualized education plans are the key tools for special education professionals and can be life changing for students. An Individualised Education Plan (IEP) must be designed specifically for the needs of each student, which requires collaboration between special education teachers, associated services, general education teachers, and caregivers. Individual education plans must be child-centred, inclusive, holistic, collaborative, and accessible. This collaboration is even harder to achieve in today's new, pandemic driven, remote learning environments, wherein these vital relationships often have not been built in person and data/test results are updated less frequently. In many remote learning scenarios, many parents are worried that pre-pandemic IEP plans may leave children without direct support from schools.

\section{Results}

This study was conducted in order to examine the opinions of special education teachers working with students (grade 1-12) with learning disabilities in general education institutions during the COVID-19 pandemic. The study was conducted by distributing questionnaires via Google Forms. During this research, 70 special education teachers were surveyed. The author designed a questionnaire as a data collection instrument to explore the opinions of 70 special education teachers in Latvia. All of the special education teachers were females. Teachers are randomly selected in order to ensure that participating teachers truly represent the variety of schooling available in the country. 7 questions were included in the survey. Survey questionnaires are voluntarily completed by respondents. 
Research questions referred to alternative tools used by special education teachers (see Fig. 1). For instance, what kind of alternative communication and cooperation platforms or other e-learning were used during the school year?

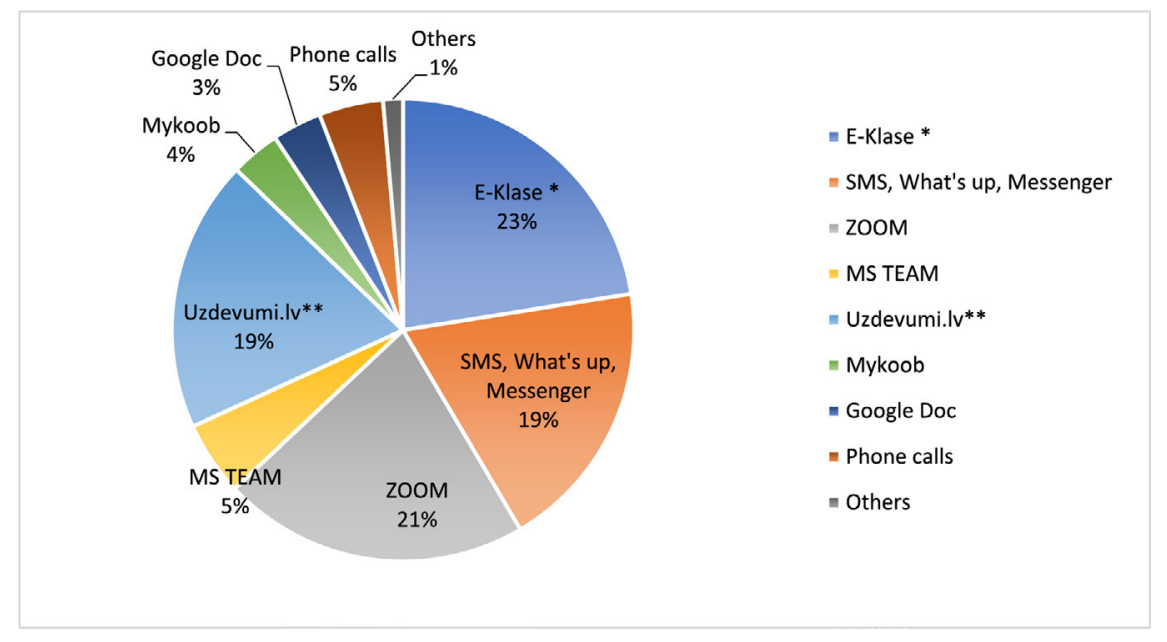

Figure 1. E-learning platforms

The special education teacher at the public school used mostly WhatsApp to connect with their students. WhatsApp, SMS, and Messenger (19\%) were used to send and receive homework and other assigned tasks. The digital platform with the highest percentage of use was E-Klase* (E-class) - 23\%. E-Klase is the most commonly used online learning management system in Latvia. E-Klase is used by more than $90 \%$ of Latvian educational institutions. Meanwhile, Uzdevumi.lv** - at 19\% - has developed a digital learning platform that can be used in schools in the daily education and learning process. Uzdevumi.lv's platform includes theory, tasks, and tests for grade 1-12 students.

Collaboration platforms that support live-video communication mostly was Zoom, with a usage percentage of $21 \%$, MS Team - only 5\%. Less frequently collaborative document tool - Google Docs (3\%) and learning managment system - Mykoob (4\%) in online learning during COVID-19. Respondents also mentioned reported the use of other minor digital platforms; their uses total together at $1 \%$.

In the survey, special education teachers mentioned that additional support measures were introduced in the learning process for all students with learning disabilities, not just for those with learning disabilities. Remote learning does present constraints to traditional instruction, and many mentioned that it took more time and work for students, parents, and teachers 
(70\% of respondents). During the COVID-19 pandemic, the individualised education plan was adapted for students with learning disabilities, but the survey concluded that it was not individualised towards students in all schools (see Fig. 2).

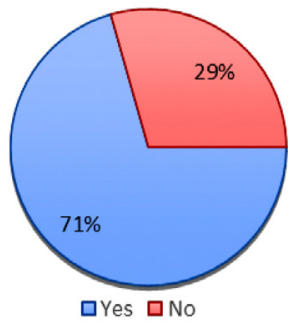

Figure 2. Adjustment of the individualised education plan

Yet this also presents teachers with alternatives to traditional education methods. In addition, the learning process was organised with the inclusion additional support methods (see Fig. 3). Some further benefits include:

- Individual lessons on Zoom platform with specialists (special education teacher, educational psychologist, speech and language therapist) and the subject teacher.

- Additional face-to-face consultations being provided, taking into account the relevant epidemiological safety measures.

- Reduced amounts of homework.

- Creating a structured weekly plan for students.

- Time extension for tasks.

- Revised and reduced curriculum.

- Tests are written individually or in small groups (2-4 pupils).

- The online lessons can be held with a special teacher.

- Digital reminders.

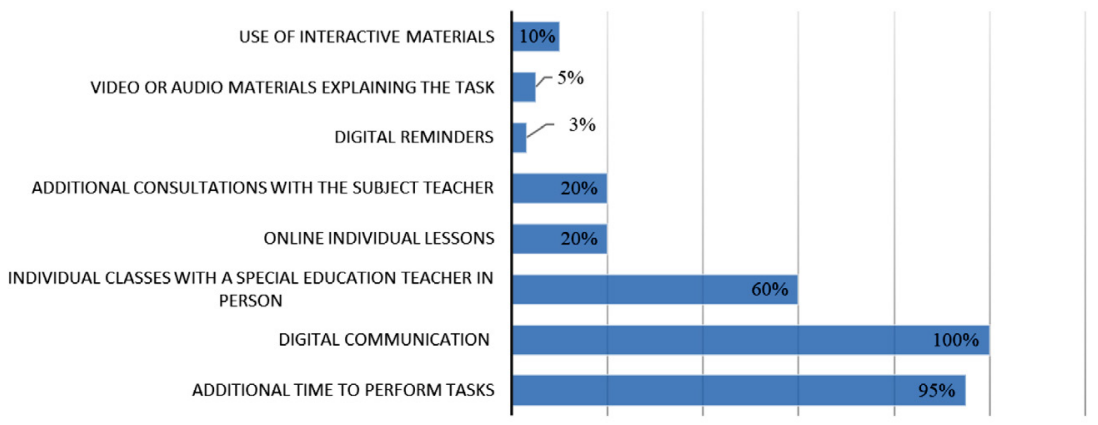

Figure 3. Additions to the individualised education plan 
Although $71 \%$ of respondents indicated that the IEP was adapted, it can be seen (see Fig. 3) that most of these adaptations were in the form of additional individual classes with a teacher or special education teacher. Rather low in frequency were the use of digital indicators, interactive materials or video, and audio materials.

\section{Challenges}

The main challenges for special education teachers are mentioned below:

- The transition of lessons to the Zoom platform.

- Lack of ICT (cameras not working, slow internet, no microphone, just a phone). Equipment was, at times, worn out, not powerful enough, or in some cases parents did not want to take responsibility for the tools offered by the school. Beyond this, computer skills were occasionally lacking, including the ability to work on digital documents (downloading, saving, sending). Sometimes difficulty was faced connecting to the online platform.

- Difficulty explaining tasks or task instructions online -- lack of faceto-face contact.

- Children with learning disabilities growing tired of working on a computer; concentration lapsing, difficulty switching from a computer screen to a notebook.

- No parental support (parents work or parents cannot help with computer work). Pupils lacked the motivation to do their jobs if there was no adult at home controlling the performance children.

- Lack of social interaction. In remote learning, students' personal contact with each other and with teachers is minimal. Therefore, this form of training is not suitable for developing communication skills, confidence, or teamwork skills.

- Emotional instability of pupils.

- Communication barriers between special education teacher and students.

- Inconvenient to use a webcam. Especially if the home conditions are not favourable.

- Atmosphere at home, (not everyone has their own workplace; noise, including TV sounds in the background, as well as adult conversations, children shouting).

- The ability to schedule.

- Difficulty in working independently, inability to focus, difficulty understanding what to read. Difficulty in understanding abstract concepts or in drawing conclusions; very, very strong need for recognition, 
confirmation - 'you can, you will succeed, you have already managed it several times'; children need regular support.

- In remote learning scenarios, another trend has appeared to be more pronounced - some parents do their children's homework.

\section{Opportunities}

The special education teachers' survey mentions the benefits of remote learning, which could be introduced in the future. Some special education teachers point out that remote learning for children with learning disabilities was a very positive experience, with students spending more time on tasks, and experiencing the benefits of individualised teacher feedback as well as receiving parental assistance.

Respondents mention in their responses the following benefits:

- Opportunities to improve your knowledge and skills in using ICT. Students gained an increased understanding of how ICT can be used in learning. The special education teachers believed that remote learning is beneficial and that helping students develop ICT skills is one of the most critical positive elements.

- Closer and more frequent cooperation with the family. The students' families also participated in individual classes; they thus grew to understand exactly what help the children needed. Cooperation was also more common between pupils, teachers, special education teachers, and family.

- Schools paid more attention to the possibility of providing pupils with learning disabilities with additional individual counselling. More focus was devoted to individual work.

- Pupils who were introverted became more open and expressed their views more easily when asked unclear questions.

- Children with learning disabilities were able to complete the assigned tasks at their own pace. They could study materials at a personal speed and intensity, without having to adjust to the pace of the average classroom.

- In remote learning, children with learning disabilities who also had behavioural disabilities improved their success. This is explained by the fact that it is much more difficult to focus on the specific task in regular class.

- Students learned to handle more autonomy, as well as gained the ability to plan for their studying, and were given more responsibility for the work itself. They could make an individual study schedule for themselves.

Overall, respondents had all mentioned not only the challenges, but also the positive benefits of remote learning; this data can easily be used for 
work in the future. Notably, only one respondent believed that there were no benefits to the situation. One of the respondents also mentioned that remote learning helped with safety. By being at home, many students are able to get work done in a safe and relaxing environment. Four respondents noted that it was not necessary to spend time and finances to get to school or the workplace, and so it was convenient to arrange consultations at times convenient for everyone.

\section{Discussion}

The results of the study show that special education teachers believed remote learning to hold benefits as well as challenges. However, directing one's view from challenges to opportunities - in what ways does this 'new normal' allow for making the curriculum more accessible to students with learning disabilities?

Policy makers and education stakeholders should place special focus on students with learning disabilities to help identify the best ways to design remote learning policies - for example, the well-organised management of virtual classrooms is essential to ensure productive learning. We still have teachers who prefer their traditional, practiced methods and are not receptive of this new and innovative technology. In general, however, the number of special education teachers working in the educational institutions of Latvia who supported the implementation of remote studies during the spread of COVID-19 has increased significantly.

\section{Conclusions}

Public education's response to the coronavirus pandemic has changed teaching and learning in unprecedented ways. The closure of school buildings and the sudden transition to virtual learning last spring posed many challenges for school districts about how they may serve all students individually, including those with learning disabilities. In order to ensure that all pupils with learning disabilities have access to quality education, it is necessary to take into account their specific needs for accessible, special-tailored, and personalised education plans. Summing up the results obtained, special education teachers believe that children with learning disabilities faced personal, technical, logistical, and financial challenges during this time of the COVID-19 pandemic.

Students show a lack of purpose in completing work online, mainly due to low learning motivation, technology related problems, the remote from teachers and lack of time with them, and finally the lack of parental support. Information and communication technologies (ICTs) offer unique 
educational and training opportunities which improve both teaching and learning. Remote learning allows students with learning disabilities to learn flexibly and in balance. The survey results were not mentioned as support for outdoor education for students with learning disabilities. In the future, it would be desirable to take into account the positive benefits of this concept and use them as support measures for special educators. Special education teachers should further improve their skills to use various digital tools (applications, video and audio recording of specific substances, digital explanations of tasks, interactive learning materials in Latvian, etc.). In the future, students with learning disabilities could be served in three learning formats: in-person, hybrid, and remote - however this learning path still requires investment into a range of equipment and infrastructure, including computers, webcams, and a stable internet connection. The author agrees that nowadays, the challenges to access online learning are fewer, because both learners and teachers have now experienced the excellent opportunity of interacting with educational technology tools such as mobile-based learning, computer-based learning, and web-based learning (Pellegrini et al., 2020).

\section{References}

Avanesian, G., Mizunoya, S., Amaro, D. (2021). How many students could continue learning during COVID-19-caused school closures? Introducing a new reachability indicator for measuring equity of remote learning. International Journal of Educational Development 84:102421. https://doi.org/10.1016/j.ijedudev.2021.102421

Azevedo, J. P., Hasan, A., Goldemberg, D., Iqbal, S. A., Geven, K. (2020). Simulating the Potential Impacts of COVID-19 School Closures on Schooling and Learning Outcomes: A Set of Global Estimates (Policy Research Working Paper No. 9284). Washington DC: World Bank. https://openknowledge.worldbank.org/handle/10986/33945

Brossard, M., Cardoso, M., Kamei, A., Mishra, S., Mizunoya, S., Reuge, N. (2020). Parental Engagement in Children's Learning: Insights for remote learning response during COVID-19 Innocenti Research Briefs No. 2020-09, UNICEF Office of Research, Innocenti, Florence.

Education: From disruption to recovery. (2021, June 2). UNESCO. https://en.unesco. org/covid19/educationresponse

Kaffenberger, M., Pritchett, L. (2021). A Structured Model of the Dynamics of Student Learning in Developing Countries, with Applications to Policy. International Journal of Educational Development. 82, 102371. https://doi.org/10.1016/j.ijedudev.2021.102371

Ma, K., Chutiyami, M., Zhang, Y., Nicoll, S. (2021). Online teaching self-efficacy during COVID-19: Changes, its associated factors and moderators. Education and Information Technologies. Published. https://doi.org/10.1007/s10639-021-10486-3

Pellegrini, M., Vladimir, U., Nunzio, C. (2020). Reimagining and Re-Designing the Post-COVID-19 Higher Education Organizations to Address New Challenges and Responses for Safe and Effective Teaching Activities (July 16, 2020). Law and Economics Yearly Review Journal - LEYR. 9(1), 219-248. Available at SSRN: https://ssrn.com/ abstract $=3659062$ 
Pokhrel, S., \& Chhetri, R. (2021). A Literature Review on Impact of COVID-19 Pandemic on Teaching and Learning. Higher Education for the Future, 8(1), 133-141. https://doi. org/10.1177/2347631120983481

Qazi, A., Qazi, J., Naseer, K., Zeeshan, M., Qazi, S., Abayomi-Alli, O., Ahmad, I. S., Darwich, M., Talpur, B. A., Hardaker, G., Naseem, U., Yang, S., Haruna, K. (2021). Adaption of distance learning to continue the academic year amid COVID-19 lockdown, Children and Youth Services Review, 126, 106038, https://doi.org/10.1016/j. childyouth.2021.106038.

Saidi, R. M., Sharip, A. A., Abd Rahim, N. Z., Zulkifli, Z. A., Md Zain, S. M. (2021). Evaluating Students' Preferences of Open and Distance Learning (ODL) Tools. Procedia Computer Science, 179, 955-961, https://doi.org/10.1016/j.procs.2021.01.085.

Sheen, A., Ro, G., Pinheiro Dos Santos, A., Kagadkar, F., \& Zeshan, M. (2020). 51.15 SCREEN TIME IN THE CONTEXT OF COVID-19: THE GOOD, THE BAD, AND THE UGLY. Journal of the American Academy of Child and Adolescent Psychiatry, 59(10): S255. https://doi.org/10.1016/j.jaac.2020.08.425

The Ministry of Education and Science (Izglitiības un zinātnes ministrija), Edurio, (2020). Mācību gada noslēguma aptaujas IZM un Edurio aptauju rezultāti. https://home.edurio. com/izm-gada-nosleguma-aptaujas 